\title{
Early Book Collections and Modern Audiences: Harnessing the Identity/ies of Book Collections as Collective Resources
}

\begin{abstract}
This article summarizes and contextualizes the discussions of a workshop held at Durham University in November 2018. In this workshop, participants (including academics, students, independent scholars, special and rare books librarians, and archivists) discussed the notion of the collection (that is, the identity of collection as a whole, rather than just its constituent parts), and its potential to serve as a means of engaging both scholarly and public audiences with early book cultures. This study sets out a series of considerations and questions that might be used when tackling such special collections engagement projects, including ones involving more modern collections than the case studies examined here.
\end{abstract}

In November 2018, the Institute for Medieval and Early Modern Studies at Durham University kindly funded a workshop to investigate the ways in which contemporary audiences have been, are being, and can become engaged with medieval and earlymodern book culture through the provision and distribution of key resources. These resources range from published books to digital artefacts and editions; from replica teaching kits—such as scriptorium suitcases - to physical archives and repositories. ${ }^{1}$ The aim of the workshop, which was led by one of this article's two authors (Leah Tether), was to build a picture of best practice to inform the teaching and commu-

1. The authors are grateful to Durham's Institute for Medieval and Early Modern Studies for funding the workshop, and to the administrators of the Residential Research Library Fellowships (jointly organized by Ushaw College and Durham University) that enabled Leah Tether to spend time in Durham in November 2018. The authors are also grateful to the various contributors and participants at the workshop, whose ideas and comments are to be found interwoven throughout this article. They are: Professor Barbara Ravelhofer (Department of English Studies, Durham University), Dr. Richard Allen (Archives, St Peter's College, University of Oxford), Dr. Erik Niblaeus (Department of History, Durham University), Dr. Michael Stansfield (Archives and Special Collections, Durham University Library), Dr. Richard Higgins (Special Collections, Durham University Library), Dr. Louise Hampson (Centre for the Study of Christianity and Culture, University of York), Dr. James Freeman (Special Collections, Durham University Library), Dr. Samantha Rayner (Centre for Publishing, UCL), Linda Gowans (Independent Scholar), Charlotte Spencer (PGR, Durham University), Anna Begley (UG, Durham University), Hannah Piercy (PGR, Durham University), Dr. Marc Schachter (Department of French, Durham University), Dr. Charles C. Rozier (Department of History, Durham University), Dr. Natalie Goodison (Department of English Studies, Durham University), Dr. Danielle Westerhof (Rare Books, Durham University Library). 
nication of early book cultures in higher education and beyond. The case studies offered by participants, including the second author (Laura Chuhan Campbell), highlighted the kinds of resources and methods that best serve to communicate the uniqueness of early book collections, particularly when attempting to foster dynamic interplay between academic and wider audiences. At the heart of this was the notion of identifying and harnessing the specific identity/ies of book collections as a means of achieving that end; in short, the workshop asked if there were anything to be gained by thinking about book collections in their entirety, rather than through their constituent parts. This article aims to summarize and contextualize the findings of the Durham workshop. It will do so, first, by explaining the background and context of the project and, second, by setting out the key findings of the workshop under the four areas of confluence that emerged as a result of the discussions: "The Collection's Identity/ies," "Identifying the Audience," "Discoverability," and "Teaching." While our core focus is on early book collections (medieval and early-modern), and case study examples will come from these periods, many of the core principles expounded across these four areas are just as relevant to more modern collections.

\section{Context}

This inquiry was inspired by a slightly different, but related, project, which examined the ways in which the often inaccessible book products of medieval France had been made accessible to specialists and nonspecialists alike through modern publications. Penguin Books' Classics imprint was a core area of inquiry in this study, and Tether, basing her research on the editorial files contained in the Penguin Archive in the University of Bristol's Special Collections, wrote a short-form monograph for Cambridge University Press' Elements series. This study considered the drivers for publishing medieval French in translation on Penguin Classics between ca. 1956 and $2000 .^{2}$ The primary evidence that related to Penguin's publication of medieval French texts suggested that, while Penguin cited a general readership as the target audience for its titles, the publication process was in fact driven behind the scenes by quite explicit academic and pedagogic needs, such as the expanding university system in both the UK and US. The link to the present project came when noting the fact that the Penguin list, when considered together as a collection, operates as a kind of educational resource in its own right. As Malcolm Bradbury writes in his foreword to Fifty Penguin Years, "The huge list of titles in print [on Penguin] makes up a vast modern university." 3 The idea that a collection of books could be perceived as forming an educational resource led to a consideration of the potential value of other kinds of book collections in their guise precisely as collec-

2. Leah Tether, The General Reader and the Academy: Medieval French Literature and Penguin Classics (Cambridge, UK: Cambridge University Press, 2019).

3. Malcolm Bradbury, "Foreword," in Fifty Penguin Years: Published on the Occasion of Penguin Books' Fiftieth Anniversary, ed. Penguin Books (Harmondsworth, UK: Penguin, 1985), 7-9. 
tions for engaging modern audiences with unfamiliar book cultures, particularlybut not limited to-premodern ones. In other words, collectors often bring their groups of books and book fragments together in circumscribed ways; thus, they usually operate according to some kind of governing principle. A collector whose practice is truly haphazard is unusual indeed. Each item in a collection therefore represents, consciously or otherwise, a constituent part of the larger jigsaw that is the collection itself. If taken together, the collection's potential value thus promises to be greater than the mere sum of its parts. To illustrate this more clearly, we now offer four brief examples of collections and their collectors.

The first example is Matthew Parker (1504-1575), successively Bible Clerk, Fellow and Master of Corpus Christi College, Cambridge, and Archbishop of Canterbury to Queen Elizabeth I. Parker's manuscript and printed book collection now makes up the Parker Library at Corpus Christi College, Cambridge. As is true of most collectors, Parker did not gather his books arbitrarily; rather, many of the books that found their way into Parker's collection came to him by royal order, as decreed in a Privy Council broadsheet of 1568, which, in the interests of the "conseruation of such auncient recordes and monuments, written of the state and affaires of these her [Queen Elizabeth's] realms of Englande and Irelande," ${ }^{4}$ required that private individuals owning such books would pass them to the Archbishop of Canterbury for study and collation. R. I. Page thus describes Parker as a "one-man Royal Commission on Historical Manuscripts." Even if "conservation" might not be considered the most appropriate term for some of Parker's practices nowadays, ${ }^{6}$ it is at least clear that his collecting activity was driven most particularly by national historical interests, just as Parker's 1711 biographer John Strype sets out:

The world is for ever beholden to him [Parker] for two things: Viz., for retrieving many antient Authors, Saxon and British, as well as Norman, and for restoring and enlightening a great deal of the antient History of this noble Island. [...] Indeed he was the chief Retriever of that our ancient Native Language, the Saxon I mean, and encouraged heartily the Study of it $[\ldots]$ He was therefore a mighty Collector of Books, to preserve, as much as could be, the antient Monuments of the learned Men of our Nation from perishing. ${ }^{7}$

Parker's collection as a whole, therefore, provides a cross-section of the kinds of

4. Cambridge, Corpus Christi College, MS 114, 49. [Manuscript has been renamed recently: MS $114 \mathrm{~A}]$

5. R. I. Page, Matthew Parker and His Books: Sanders Lectures in Bibliography Delivered on 14, 16, and 18 May 1990 at the University of Cambridge (Kalamazoo, MI: Medieval Institute Publications, 1993), 44.

6. Page, Matthew Parker and His Books, 45-61.

7. John Strype, The Life and Acts of Matthew Parker (London, UK: John Wyatt, 1711), 524, 528, 535. 
works that - in the mid-sixteenth century-would have been understood as cornerstones in national identity formation. Thus, these books, each of which has its own value, come together as a group to tell us something even more significant.

A similar case is provided by Robert Cotton (1571-1631) who, in the late sixteenth and early seventeenth centuries, amassed a collection of manuscripts that outstripped even the Royal Collection. His books, rather like Parker's, were intended to facilitate the study of English history, literature, and antiquities. He was, however, slightly less focused in his subject choices than Parker, sometimes allowing other types of books to enter his collection. ${ }^{8}$ Perhaps most important, though, Cotton counted himself not only as a collector, but also as a great student of the books he owned, and set up schemes whereby others could become the same; indeed, he proudly allowed his books to be borrowed as a kind of public service. ${ }^{9} \mathrm{He}$ also made generous donations of books to the founding of great libraries, including the Bodleian upon its establishment by Sir Thomas Bodley in $1601 .{ }^{10}$ Cotton even jointly petitioned Queen Elizabeth to open a library and an associated "Accademye for the studye of Antiquity and Historye." ${ }^{\prime 11}$ As a group, then, Cotton's book collection shows us how education with respect to national history developed into the seventeenth century after Parker. Cotton, however, was perhaps less interested in early book production practice than Parker had been, since not a single one of his books retains its original binding. Indeed, Cotton's conscientious instructions on the rebinding of his books are well documented, which suggests that he was rather more interested in developing a consistent physical identity for his collection, rather than showcasing matters of book history as such. ${ }^{12}$

Even in more recent centuries, while we find other collectors with gathering practices rather different from those of both Cotton and Parker, many of them nonetheless have similar preoccupations with establishing a particular identity, physical or conceptual, for their collections. A useful example of this is provided by the Rouse Collection at UCLA. According to the UCLA website, noted manuscript scholars Richard H. Rouse and Mary A. Rouse brought together their collection of 113 medieval manuscripts and 78 leaves and documents with a very clear purpose in mind: to provide a range of examples of book production culture, such that the collection together showcases the commissioning, making, reading, study, and

8. H. I. Bell, "Introduction," in A Guide to a Select Exhibition of Cottonian Manuscripts in Celebration of the Tercentenary of the Death of Sir Robert Cotton (London, UK: British Museum, printed by Oxford University Press, 1931), 3-11.

9. Bell, A Guide to a Select Exhibition of Cottonian Manuscripts, 6-7.

10. Bell, A Guide to a Select Exhibition of Cottonian Manuscripts, 3-4.

11. See the $c .1589$ draft petitions from "Mr. Cotton," "Mr. Dodorug," and "Mr. James Lee" for presentation to Queen Elizabeth I in London, British Library, MS Faustina E. v., fol. $89^{\mathrm{r}}$ and London, British Library, MS Titus B., v., fol. $210^{\mathrm{r}}$.

12. Bell, A Guide to a Select Exhibition of Cottonian Manuscripts, 8. 
dispersal of handwritten books in the broadest manner. ${ }^{13}$ It is described precisely as

a teaching collection that includes examples, often fragmentary, of many different sorts of manuscripts whose forms and scripts represent the widest possible variety of times, places, genres, and Western languages, and comprises not only Latin but vernacular texts as well. ${ }^{14}$

A further modern collection of early books whose use as a teaching tool is foregrounded by its host repository is that gathered by Professor Toshiyuki Takamiya. His collection of Middle English manuscripts is now held at the Beinecke Library at Yale University. It is, the Yale website claims, "the largest, most comprehensive and finest collection of medieval English manuscripts assembled in modern times." 15 Takamiya specifically cited his wish for his collection as a whole to be housed at the Beinecke and used for pedagogical purposes, because of the light it sheds on English and Latin textual traditions. For example, he gathered multiple copies of the same text to demonstrate matters of textual variance across manuscripts. ${ }^{16} \mathrm{But}$ Takamiya also displayed discernment as a collector at moments where he opted not to purchase certain books. For example, he decided against adding the so-called Winchester manuscript of Sir Thomas Malory's Le Morte Darthur (now London, British Library, MS Additional 59678) and the Booke of Margery Kempe (now London, British Library, MS Additional 61823) to his collection, despite having been offered the opportunity to do so. He felt that these books should stay in England because they were crucial elements in the country's historical patrimony and therefore did not belong in a Japanese collection. ${ }^{17}$ This, in itself, says something very particular about how we should understand the group of books that he did allow to enter his collection.

The modern collections of Richard and Mary Rouse and Toshiyuki Takamiya were therefore gathered and curated to teach modern audiences about early book and textual cultures, and such objectives have been explicitly acknowledged by the collectors themselves. Similarly, historic book collectors such as Cotton and Parker

13. Dawn Setzer, "UCLA Library Received Richard and Mary Rouse Collection of Medieval and Renaissance Manuscripts," UCLA University News, February 23, 2006, http: / / newsroom.ucla.edu/releases / UCLA-Library-Receives-Richard-and-6847 [accessed November 28, 2018].

14. Online blurb to the printed catalogue for the collection, ACMRS, https://acmrs.org/publications / catalog/medieval-and-renaissance-manuscripts-ucla-library-special-collections-i-richard [accessed November 28, 2018]. Setzer's "UCLA Library" also describes the collection as "useful for teaching."

15. Online Exhibits@Yale, "Making the Medieval English Manuscript: The Takamiya Collection at the Beinecke Library," http:// exhibits.library.yale.edu/exhibits/show/making-the-english-ms [accessed November 28, 2018].

16. Online Exhibits@Yale, "Making the Medieval English Manuscript"; see also the various essays in The Medieval Book and a Modern Collector: Essays in Honour of Toshiyuki Takamiya," eds. Takami Matsuda, Richard A. Linenthal, and John Scahill (Cambridge, UK: D.S. Brewer, 2015).

17. Online Exhibits @Yale, "Professor Takamiya as Collector," http://exhibits.library.yale.edu/exhibits/show/making-the-english-ms/professor-takamiya-collector [accessed November 28, 2018]. 
seem to have had equally unambiguous intentions of educating audiences through the provision of their collections as wholes. The Durham workshop, then, started from the premise that early book collections - and book collections more generally_are resources whose value may be most potent when they are considered together. This is in no way intended to undermine the value of researching individual items within a collection, but rather to suggest that, by taking a step back and considering the motivations of the collector and/or the identity/ies of the collection, the collection as a whole may be able to shed new light on its constituent parts and on wider socio-historical questions and debates. The vital question that the workshop sought to answer, therefore, was this: how can we reconnect modern audiences with a collector's intentions and thus the identity of a given collection? In other words, what can we do in practical terms to harness, understand, and showcase more effectively such collections in their entirety as collective resources?

What follows is a recapitulation of the workshop's findings, considered and contextualized alongside examples of current practice. The overarching aim of this article, though, is not to give directives, but rather to raise and discuss the kinds of questions and issues that workshop contributors felt would be helpful for scholars, librarians, archivists, and others to consider when tackling projects that attempt to engage audiences with early book collections. Furthermore, these questions and guiding principles have been set out in such a way as to give them additional relevance in respect of more modern collections, too.

\section{The Collection's Identity/ies}

Central to the workshop, as discussed above, was the idea that a collection's particular identity might be the key to creating a suitable platform for it, which would give prominence to the full range of its holdings. The question, however, was how to identify that identity. Does it start with the collector and his/her motivations? Or have new identities emerged and/or developed as collections have been curated over time and by different agents? Of course, the four examples briefly discussed above all worked from the premise that the collector's motivations were at the heart of the exercise. After all, if a collection was originally gathered for a circumscribed purpose, and that purpose is known or can be surmised, then using or displaying that collection under that light may be relatively straightforward. However, this relies upon there being some form of documentary evidence of a collector's approach — which is not always available — or a self-evident coherence to the collection's holdings. It is considerably more problematic where collectors are not obviously strategic and focused, as was illustrated particularly vividly by the case study presented by James Freeman of the Cambridge University Library's Special Collections team. Freeman's example was the collection of manuscripts and books donated/sold to Cambridge University Library by F. J. Norton (d. 1986), a 
long-serving member of the library's staff, a bibliographer and Hispanist. ${ }^{18}$ Norton, Freeman explained, collected more or less anything he could lay his hands on that was in some way related to his broad interests, leading Freeman to label the Norton Collection as an "anti-collection collection." Therefore, in the case of a collector like Norton, who sometimes gathers his/her books haphazardly, establishing a collection's identity through the collector's particular approach is often not possible.

Even where the original collector had identifiable reasons for collecting the items $\mathrm{s} /$ he did, the incorporation of these items into other collections over time means that such identities can develop, become multiple or are superseded. It is possible to conceive, for example, of a collection such as Norton's as eventually acquiring an identity through such means, even if we cannot yet imagine what that might be. Indeed, where one collection now forms part of another collection, we might well ask which collection's identity should be showcased. Alternatively, where individual items in collections have, through scholarship, exhibitions, and curation, become particularly prominent ("star attractions" of sorts), the collections in which they are contained can become overshadowed and, eventually, neglected. Richard Allen (Archives, St Peter's College, Oxford) provided an example of this with his case study of the Ellesmere Collection (also known as the Egerton Family Papers or the Ellesmere Manuscripts) at the Huntington Library, whose roughly 13,000 items are particularly rich in vernacular manuscripts and political and legal papers. ${ }^{19}$ Allen demonstrated that the existence of a Chaucer manuscript within the collection (the so-called "Ellesmere Chaucer"; San Marino, Huntingdon Library, MS EL 26 C 9) 20 $^{20}$ has had the effect of rendering the rest of the collection practically invisible. The same example, moreover, gave rise to a crucial issue of the link between nomenclature and identity. For instance, the name "Ellesmere" is now inextricably associated with the Chaucer manuscript to the extent that typing "Ellesmere Collection" into Google leads to several pages about the Chaucer manuscript before any mention is seen of the wider collection in which it is contained. Could, therefore, the Ellesmere Collection's identity be renewed by adopting one or another of its other monikers as a means of distinguishing the collection from its particularly famous item? Can the name of a collection, in other words, make or break its potential as a tool for engaging wider audiences?

Erik Niblaeus (Department of History, Durham University) also broached the problem of the collection's identity in respect of the Scandinavian fragments that

18. Cambridge University Library, "Norton Collection," www.lib.cam.ac.uk/collections/departments/rare-books/collections/norton-collection [accessed November 28, 2018].

19. Online Archive of California, "Egerton Family Papers: Finding Aid," https://oac.cdlib.org/findaid/ark:/13030/c8mw2nvw/entire_text/ [accessed November 28, 2018].

20. Available in digital facsimile at Huntingdon Library, "Canterbury Tales," https:// hdl.huntington. org/digital/collection/p15150coll7/id/2838 [accessed November 28, 2018]. 
provided the subject matter for his case study. The fragments in question number more than 22,500 and are today conserved in the National Archives (Riksarkivet) in Stockholm, Sweden. ${ }^{21}$ They are heterogeneous items from a wide range of book types and were typically found reused in the bindings of books that had been earmarked, in their own turn, for destruction (for example, out-of-date books from parish churches). Importantly for our discussion, these fragments were not originally brought together to form a collection per se. Their formation as a collection has rather, somewhat ironically, only come about thanks to processes of destruction - twice over, in fact: first, the destruction of the original book that contained the fragment; and, second, that of the later book into which the fragment had found its way. ${ }^{22}$ However, Niblaeus acknowledged that there is something cohesive in the notion of destruction, and it speaks to a current vogue among scholars and even beyond the academy - that is, the fascination for what is lost or missing. ${ }^{23}$ Even if the collection was not brought together to establish a particular identity, it has nonetheless managed to assume one; it is this identity, moreover, that enables the collection - as just one of several possibilities - to inform us about the types of medieval (and later) books with medieval fragment-wrappers that were considered disposable. And, of course, this is information that is only accessible by virtue of studying the collection as a whole. But a question remains: even if such an identity can be established, for whom is it interesting? Does the value of a collection's identity, in fact, depend upon the identification and subsequent buy-in of the audience to be reached?

\section{Identifying the Audience}

Regardless of the type of product being marketed, it is a foremost principle of marketing practice that, to reach an audience, it is crucial to begin by identifying and understanding that audience - in other words, to develop a profile of who they are. Only once that step is completed should a product be created with which to reach them, bearing in mind their probable likes, needs, and interests. ${ }^{24}$ Louise Hampson (Centre of Christianity and Culture at the University of York) used her case study

\footnotetext{
21. A database of the fragments, only available in Swedish, is under development: Riksarkivet, "Riksarkivet databas över medeltida pergamentomslag," https:// sok.riksarkivet.se/mpo [accessed November 28, 2018].

22. A useful English-language overview is provided by Jan Brunius' archival guide, From Manuscripts to Wrappers: Medieval Book Fragments in the Swedish National Archives (Stockholm, Sweden: Riksarkivet, 2013).

23. See, for example, Lost Books: Reconstructing the Print World of Pre-Industrial Europe, eds. Flavia Bruni and Andrew Pettegree (Leiden, Netherlands: Brill, 2016); Thomas Haye, Verlorenes Mittelalter: Ursachen und Muster der Nichtüberlieferung mittellateinischer Literatur (Leiden, Netherlands: Brill, 2016); Alexandra Hill, Lost Books and Printing in London 1557-1640: An Analysis of the Stationers' Company Register (Leiden, Netherlands: Brill, 2018); Kenneth Baker, On the Burning of Books: How Flames Fail to Destroy the Written Word (Chicago, IL: University of Chicago Press, 2016).

24. Claire Squires, for example, sets out this principle in respect of marketing books in her Marketing Literature: The Making of Contemporary Writing in Britain (Basingstoke, UK: Palgrave, 2007), 51.
} 
to raise precisely this point. In specifics, Hampson showed how the selection of an intended target audience often requires the concomitant identification of multiple narratives or identities for a collection, and then a judgment as to which will provide the best vehicle for reaching that audience.

Her chosen collection consisted of a series of manuscript volumes containing the notes about York Minster, the city of York, and its diocese, made by the antiquarian James Torre (d. 1699, notes made c.1675-c.1691). These are held today in the York Minster Archives. ${ }^{25}$ Hampson emphasized that the value of the collection lies in its ability to be interpreted in multiple ways. First, she discussed the collection's place in the history of travel writing, because some of Torre's work has been described as providing one of the earliest known examples of a travel guide to York. Second, Hampson described the collection as providing a picture of antiquarian preoccupations and practices in Torre's time. Third, Torre's manuscripts, Hampson suggested, shine a light on other collections, namely those that were available in the York Minster Archives at the point at which Torre was working, in turn offering an opportunity to learn about the influence(s) of those collections on Torre's own collecting practice. Hampson thus suggested that different audiences might engage with each of these "angles"; for example, local historical interest groups and a wider public might be most engaged by the travel guide narrative, while those with interests in bibliography and archival practice might be more likely to show an interest in the other possibilities. Even where such synergies are identifiable, though, the workshop attendees questioned by what means these audiences might actually discover a collection and access it, either physically or virtually.

\section{Discoverability}

While the issue of discoverability was picked up in relation to all of the case studies presented at the workshop, it was perhaps most vividly illustrated by Campbell's case study of the collection of roughly 600 French items once owned by Bishop John Cosin (d. 1672), which now form part of the "Bishop Cosin's Library" collection in Durham University's Special Collections housed at Palace Green Library. ${ }^{26}$ Campbell confessed that, despite having been a French scholar at Durham for many

\footnotetext{
25. Torre's manuscripts are catalogued by The National Archives as being among the "Historical Compilations concerning York Minster" held in the York Minster Archives. The manuscripts by Torre or containing material related to him have shelfmarks of: York, York Minster Archives, MSS L1/2-12. For more detail of their contents, see the overview provided by The National Archives, "Historical Compilations concerning York Minster," http:/ / discovery.nationalarchives.gov.uk/details/r/ 5094fbed-ea62-49f2b525-f0af7963c3ea [accessed November 29, 2018].

26. For more information on Cosin's collecting practices, see A. I. Doyle, "John Cosin (1595-1672) as a Library Maker," The Book Collector 40 (1991): 335-57 and A. I. Doyle, "The Cosin Manuscripts and George Davenport," The Book Collector 53 (2004): 31-45. On Cosin's French books in particular, see S.R.A. Proctor, "A Study of the Printed Books in French in Bishop Cosin's Library" (MA diss., Durham University, 1974).
} 
years, she had not yet found an opportunity to engage with Cosin's French books. She believed that the core reason had to do with the fact that early-book scholars, as well as of wider audiences, will generally turn to the internet when undertaking initial scoping of repositories for potential projects/interests, searching for information on Google, a dedicated website, or both. Similar to Allen's example of the Ellesmere Collection, indeed, attempting to research "Bishop Cosin's Library" using Google leads to considerably more hits that pertain to the physical building housing the books, also called "Bishop Cosin's Library," than to the collection itself. No simple and straightforward list of the titles contained within Bishop Cosin's Library is to be found online. Therefore, if the interested party wishes to find out more, $\mathrm{s} /$ he must make a more significant investment of both time and money to travel to the repository, entailing a risk of discovering only after the event that there is in fact little of relevance in the holdings. In an age where both researchers' time and spending are increasingly pressured, the inability to find what is needed via digital means might well put off even the more tenacious among them.

Inevitably, therefore, discussions turned to the importance of cataloguing, digitization, search functions, websites, search engine optimization, unique identifiers, key words, and collection-level descriptions. It goes without saying that good practice in deploying each of these tools was felt to play a crucial role in the initial discovery and subsequent understanding of collections, which is why they will not be discussed in more detail here. More importantly, however, it was agreed that poor practice in the use of these tools risks being more detrimental than not deploying them at all. Turning once again to Bishop Cosin's Library as an example, the associated collection-level description is most easily found not via Durham's own "Discover" search function, but via Google (when typing in "Bishop Cosin's Library"). ${ }^{27}$ Even then, the hit only comes about halfway down the second page. More problematic than this, however, is that the hyperlink handoff from this description to the catalogue, which is supposedly designed to restrict a search to items contained in Cosin's collection, does not in fact perform this function. Rather, the link leads to a list of all items containing the term "Cosin Collection" somewhere in their metadata, which comprises some 5,538 items. Even a seasoned researcher in this scenario would find themselves unsure as to which items were in fact part of the collection in question; so, for an even broader, less specialist audience, the problem might seem especially off-putting and even insurmountable.

27. Durham University Library, "Collection-level Description: Bishop Cosin's Library," http:/ / discover.durham.ac.uk/44DUR_VU1:CSCOP_ALL:44DUR_EAD_DSCollection.13 [accessed November 28, 2018]. Collection-level descriptions have, in fact, long been posited as beneficial to the discoverability of collections, even well before the super-fast internet age; see, for example, Richard Saunders, "Collection or Archival-Level Description for Monograph Collections," Library Resources and Technical Services 38, no. 2 (1994): 139-47. 
The workshop's participants thus concluded that where sophisticated digital finding tools, for reasons of time and financial resource, could not be created or maintained to the highest levels, it would be helpful also to provide, via digital platforms such as the website, more "analogue" routes into the collections. For scholars, on the one hand, this might simply include PDFs of the sorts of simple handlists that libraries tend to keep under the counter in reading rooms. Where more resource is available, dedicated centers for excellence ${ }^{28}$ or visiting opportunities for researchers can bring new light to collections through the publication of new research inspired by means of privileged collections access. ${ }^{29}$ Several examples of best practice were identified in relation to the engagement of wider public audiences. For example, as well as the perhaps obvious (and costly) example of putting on public exhibitions and associated talks/ events, Michael Stansfield and Richard Higgins from Durham University Library's Special Collections pointed to the series of "Treasures of" volumes that Durham scholars had published and that provide accessible, attractive, and affordable introductions to the collections' most important items, ${ }^{30}$ while special collections blogs foregrounding "items of the week" provide a cost-effective opportunity for social media campaigning, even if they do require dedicated staffing to write/commission, edit, and publish the blog posts. ${ }^{31}$ Samantha Rayner (Centre for Publishing, UCL), meanwhile, asked whether official recognition via a successful application to the UK Arts Council's "Designation Scheme," which claims to identify, celebrate, and safeguard collections that "deepen our understanding of the world and what it means to be human," ${ }^{32}$ might help in engaging public audiences. Participants saw the potential value but also questioned the subjectivity and fairness of schemes offering this kind of "status," therefore bringing the conversation back to the question of audience-since what is valuable to one audience might well be of less interest to another. For all their benefits, moreover, it was also

28. For example, the Lincoln Unlocked project established by Lincoln College, Oxford has solicited philanthropic help to enable the creation of the Lincoln College Centre for Archives, Books, and Collections, which seeks to champion new platforms for the associated College special collections, including digitization, lectures, summer schools, and workshops: https://www.lincoln.ox.ac.uk/LincolnUnlocked. Leah Tether would like to thank Sarah Cusk, Lincoln College's Antiquarian Cataloguer, for taking the time to talk her through the project's aims and objectives.

29. Durham University's new Residential Research Library Visiting Fellows scheme provides an example: https://www.dur.ac.uk/news/newsitem/?itemno=30357, though as yet researchers do not gain privileged access through this scheme to collections in the sense of having a reserved workspace in the library or out-of-hours access as offered by other library fellowships at institutions such as the John Rylands Library, Manchester; the Newberry Library, Chicago; and the Harry Ransom Center, Austin.

30. See, for example, Treasures of Durham University Library, ed. Richard Gameson (London, UK: Third Millennium, 2007), Manuscript Treasures of Durham Cathedral, ed. Richard Gameson (London, UK: Third Millennium, 2012) and Treasures of Ushaw College: Durham's Hidden Gem, ed. James Kelly (London, UK: Scala, 2015).

31. See, among the many examples, the blog sites of Cambridge University Library Special Collections (https:/ / specialcollections-blog.lib.cam.ac.uk) and the John Rylands Library, Manchester (https:/ / rylandscollections.wordpress.com).

32. Arts Council, "Designation Scheme," https://www.artscouncil.org.uk/supporting-collectionsand-archives/designation-scheme [accessed November 28, 2018]. 
recognized that such schemes, in foregrounding some items over others (in the case of the "Designation Scheme," prioritizing some entire collections over others), can risk causing the "star attraction syndrome" that Allen identified as afflicting the Ellesmere Collection.

In response to these concerns, Stansfield noted that, while it would not be within the reach of all institutions with special collections, one method by which Durham had been able to ensure that a less selective view was taken of the collections' holdings was a university appointment in the History of the Book (a post currently held by Professor Richard Gameson). The role responsibilities for this post include caring for, researching, and communicating to students and to wider audiences information about the collections in their entirety, thus ensuring that even the more obscure objects find a platform. Introducing and maintaining such an appointment indicates clearly to external audiences that early book collections should be understood as having educational value, not just because some of their constituent items contain important historical information, but because the particular makeup of the collection, the manner of gathering together the items, may say something important about what it means, and has meant, to be human. Education (or lack thereof), however, was also discussed as a potential barrier to modern audiences engaging with early book collections. In the workshop's closing discussion led by Barbara Ravelhofer (Department of English Studies, Durham University), an important point was made. Even if an audience's interest in an early book collection can be piqued in general terms by the identification and promotion of an attractive and suitable narrative or identity, and/or even if there is the money to make freely available the full contents of a given collection (via, for instance, digitization or exhibition), access to that collection will always be limited if an audience is not equipped with the basic skills needed to decode the collection's holdings.

\section{Teaching}

With this notion of education as both a barrier and a threshold to collections in mind, it was acknowledged that direct experience of early book collections can be an effective and powerful teaching tool in higher education in particular, and one that might have longer-term benefits that resolve some of the other issues raised in this article (see below). Despite the advantages of teaching using digitized manuscripts, whether for the sake of practicality and/ or conservation,,$^{33}$ allowing students the opportunity to interact directly with primary sources not only

33. See, for example, Peter A. Stokes, "Teaching Manuscripts in the Digital Age," in Kodikologie und Paläographie im digitalen Zeitalter 2/Codicology and Palaeography in the Digital Age 2, eds. Franz Fischer, Christiane Fritze, and Georg Vogeler (Norderstedt, Germany: Books on Demand (BoD), 2011), 229-45; Tara Williams, "Multimedia Learning Gets Medieval," Pedagogy 9 (2009): 77-95. 
provides an engaging material context for the period they are studying, but also introduces them to the skills and techniques employed by professional academics. ${ }^{34}$ All students present at the workshop, ranging from undergraduate to postgraduate research students, affirmed that engaging with early books had been a highlight of their studies. Teaching with original artifacts is not without its challenges, some of which overlap with the issues of accessibility and visibility of collections that are outlined above. Students require guidance and training when using catalogues, handling the artifacts, reading the text, and interpreting palaeographical and codicological information. Such considerations, as well as the potential benefits of allowing students to interact with professional archivists, would require extensive planning that may, in many cases, need to be written into the teaching timetable from the beginning.

Nevertheless, engaging students with manuscript collections could provide a solution to some of the problems outlined in this article. If equipped with basic archiving skills, could students participate in the cataloguing and identity-formation of early (and other) book collections as part of their courses? Could they help to establish an identity for the collection through blogs, online videos, or social media campaigns that would raise the profile of the collection and help to improve discoverability within academia and beyond? Perhaps the input of students-who are typically more conversant with emerging digital communications-can offer new ways to publicize the collections? If special collections were to become hardwired into the teaching timetable, then their perceived value within the university may be increased, as they become not only a teaching resource, but also a point of attraction for potential applicants.

\section{Conclusion}

This article opened by asking whether there was value in thinking about the identity/ies of early book collections in their entirety as a means of engaging modern audiences, rather than through the lens of their individual contents and, if so, how such identities might be identified and harnessed. Certainly, the various case studies have shown that we can answer the first part of this question affirmatively in the majority of cases, though parties wishing to adopt such an approach should be careful to ensure that the particular identity/ies established for a given collection actually have the potential to interest the audience being targeted. In other words, not all kinds of audiences will find the same type of narrative engaging. With respect to the second part of the question, however, this study raises more questions

34. Julie Grob, "More Than Goldleaf: Teaching Undergraduates in Capstone Courses about the Scholarly Use of Medieval Manuscripts," in Past or Portal? Enhancing Undergraduate Learning Through Special Collections and Archives, eds. Eleanor Mitchell, Peggy Seiden, and Suzy Taraba (Chicago, IL: Association of College and Research Libraries, 2012), 145-50. 
than it answers. As stated at the outset, the intention was to do precisely this, and not to be prescriptive in setting out a "one-size-fits-all" solution. This inquiry, then, had established a series of questions, issues and topics that scholars, librarians, archivists, and other stakeholders might helpfully work through when orchestrating engagement programs for early book collections. Many of these questions, moreover, might just as easily be asked in relation to more modern book collections and their associated engagement projects. However, underpinning all of the various options, solutions, and ideas, whether resource-heavy or -light, was the inescapable fact that the value of a collection only becomes meaningful if an audience, on the one hand, can find out about it and, on the other, possesses the skills needed to access and understand it. There are no easy (or cheap) solutions to the latter problem in particular, but if early (and later) book cultures were, as suggested, woven into all arts and humanities education, even if in a low-level way, the eventual result of such an aspirational investment of time and resource could lead to the automatic resolution of not only the former issue, but also many of the others raised here. 